\title{
UMA PROPOSTA DE CATEGORIZAÇÃO DOS ARTEFATOS ANTROPOMÓRFICOS NO DESIGN CONTEMPORÂNEO BRASILEIRO
}

\author{
Nathalie Barros da Mota Silveira \\ Universidade Federal de Pernambuco - UFPE \\ nathalie.motasilveira@gmail.com \\ Virginia Pereira Cavalcanti \\ Universidade Federal de Pernambuco - UFPE \\ cavalcanti.virginia@gmail.com
}

Resumo: A pesquisa a seguir apresenta os resultados da dissertação de mestrado Corpos e Faces por Todas as Partes: um estudo dos artefatos antropomórficos no design contemporâneo brasileiro. 0 objetivo principal da pesquisa foi analisar e categorizar os artefatos do design contemporâneo, desenvolvidos e publicados no Brasil entre os anos de 2000 e 2014 e que utilizam o antropomorfismo como elemento de configuração. Com a ideia de compreender a linguagem e o potencial comunicativo desses artefatos, a pesquisa se desenvolve a partir da tríade antropomorfismo-design-estética. O estudo tem caráter qualitativo e utiliza principalmente os métodos de procedimento histórico e comparativo. Os resultados da investigação sugerem a presença de três categorias e seis subcategorias de artefatos, que consistem nos diferentes propósitos da forma antropomórfica no âmbito do design brasileiro.

Palavras-chave: Antropomorfismo. Estética. Formas Antropomórficas. Design de Produto.

\begin{abstract}
The following study presents the results of the MAF dissertation Bodies and Faces everywhere: a study of the anthropomorphic artifacts in the Brazilian contemporary design. The main goal of the study is to analyze and categorize anthropomorphic artifacts from the Brazilian design, especially between the years 2000 and 2014. From the idea of comprehend the language and the communicative potential of such artifacts, this research is developed from the triad anthropomorphism-design-aesthetics. The Study is qualitative and mainly uses the historical and comparative procedure methods. The results of the investigations suggest the presence of three categories and six subcategories of artifacts that reflect the different purposes of the anthropomorphic form within Brazilian design.
\end{abstract}

Keywords: Anthropomorphism. Aesthetics. Anthropomorphic Forms. Product Design. 


\section{INTRODUÇÃO}

Segundo o antropólogo americano Stewart Guthrie, antropomorfismo é "a atribuição de características humanas a objetos e eventos não humanos" (1993, p. 3). Os teóricos da psicologia explicam que se trata de um fenômeno psicológico que se refere à capacidade inata dos homens de reconhecer, inconscientemente, traços e características humanas, a partir de mecanismos automáticos de percepção.

A predisposição de exergar rostos nas nuvens, nas formas da natureza ou em tantos outros objetos; de reconhecer expressões no front-end dos automóveis; silhuetas femininas em jarras ou frascos de perfume, são apenas alguns exemplos entre as infinitas possibilidades que demonstram a capacidade do homem em antropomorfizar, ou seja, de enxergar o mundo em sua volta em termos humanos.

De acordo com De Botton (2007, p. 89), "tão refinada é a nossa habilidade para detectar paralelos com os seres humanos nas formas, texturas e cores que podemos interpretar uma personalidade na forma mais humilde que há". Sendo assim, mesmo que esses objetos não tenham sido planejados para exibir alguma característica humana, o cérebro é capaz, ao menor estímulo, de organizar as informações e decodificá-las em termos humanos. A seguir, imagens do livro Face to Face dos irmãos suíços Jean Robert e François (Figura 1), que reune uma série de fotografias que captam características antropomórficas em objetos inanimados.

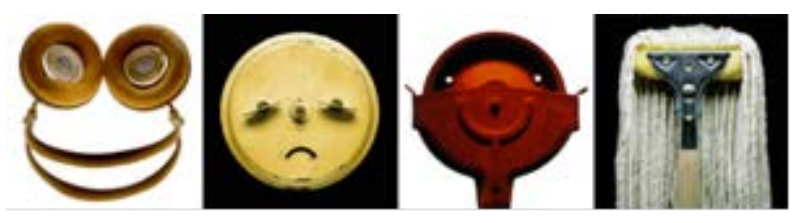

Figura 1 - Imagens do livro Face to Face.

Fonte: www.atissuejournal.com

Em paralelo a essas associações, a Arte, a Arquitetura e o Design têm usado estrategicamente desse artifício, incluindo em seus artefatos elementos ou formas que despertam os sentidos dos indivíduos com o propósito de promover a interpretação antropomórfica das coisas. Essa prática não é recente e são muitos os exemplos que servem para ilustrar esse fenômeno.

No século XVI, o pintor italiano Giuseppe Arcimboldo reproduziu em seus quadros, uma série de figuras antropomorfas nas quais a feição humana é reconstruída a partir de relevos e elementos naturais, além de outros objetos de natureza morta.

$\mathrm{Na}$ arquitetura, já no século I a.C., o arquiteto romano Vitrúvio costumava relacionar móveis e prédios com seres humanos, como diz De Botton (2007). Outro exemplo, é a Casa Dançante (Figura 2), uma dupla de edifícios projetada por Frank O. Gehry e Vlado Milunic, localizados em Praga, República Tcheca. A contrução é também conhecida como Fred \& Ginger, uma homenagem aos dançarinos Fred Astaire e Ginger Rogers. O posicionamento dos prédios sugere um casal de bailarinos. Se olharmos atentamente é possível perceber a malemolência das pernas, o balanço e a curva dos corpos, na cena em que Fred parece enlaçar a sua parceira Ginger pela cintura. 


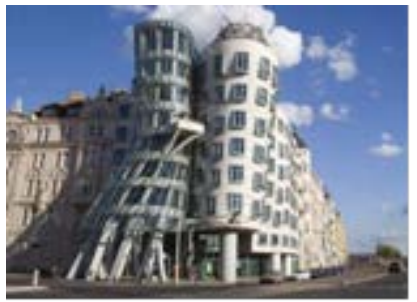

Figura 2 - A Casa Dançante (1990), de Frank O. Gehry e Vlado Milunic.

Fonte: www.laifi.com

No Design, essa prática de empregar nos artefatos aspectos físicos e comportamentais propriamente humanos tem sido muito comum. Grandes ícones, como o Bocca Sofa, produzido pelo Studio 65, no início da década de 1970, e a cadeira Up5 Donna (Figura 3), projetada por Gaetano Pesce em 1969, são exemplos claros dessa aproximação. A Up5 Donna, segundo o seu criador, foi projetada para parecer-se com as estatuetas femininas criadas na Pré-história. As formas da Up5 Donna muito se aproximam da famosa imagem da Vênus de Willendorf ${ }^{1}$.

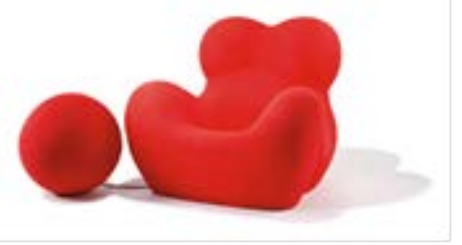

Figura 3 - Cadeira Up5 Donna (1969), de Gaetano Pesce.

Fonte: www.lamodern.com

Ressaltamos, nesse ponto, a recorrência com que o homem, no decorrer da história tem empregado atributos e caráter humanos aos objetos. Essa tendência é percebida não somente no sentido de reconhecer as formas humanas em tudo o que se vê, mas também de transpor essas características para os objetos, como uma espécie de jogo de representações entre o homem e as formas do mundo.

O fato é que designers têm identificado e utilizado esse mecanismo de percepção para propor novas possibilidades comunicativas para o design de artefatos. Compreender qual a linguagem dos artefatos antropomórficos do design contemporâneo brasileiro foi a questão principal que norteou a pesquisa.

Apesar da recorrência das formas antropomórficas como ferramenta de comunicação é possível perceber que, assim como a maioria das questões que envolvem aspectos subjetivos do design, esse é um universo teórico ainda pouco explorado. Sobre isso, De Botton (2007), explica que as discussões a respeito do potencial expressivo dos objetos ainda são raras. Parece mais confortável, por exemplo, refletir sobre assuntos mais concretos como as "fontes históricas" ou os "tropos estilísticos". Sendo assim, pensar no aprofundamento de "significados antropomórficos, metafóricos e evocativos" (DE BOTTON, 2007, p. 97) ainda parece estranho.

\footnotetext{
${ }^{1}$ A Vênus de Willendorf, ou Mulher de Willendorf, é uma pequena estatueta datada de 2500-2000 a.C., que represenra a imagem idealizada da figura feminina, com formas voluptosas, as quais se infere uma relação forte com a ideia de fertilidade.
} 
Decifrar e compreender a linguagem desses produtos oferece aporte para a ampliação do vocabulário comunicativo do design, fornecendo bases teóricas para a resolução de problemas de ordem comunicacional, de significação e de geração de sentidos dos artefatos de Design. Em outra instância, a discussão dessas questões confronta o distanciamento que existe com relação à contemplação dos aspectos subjetivos do design, que ainda persiste no pensamento contemporâneo.

Este artigo apresenta os resultados da dissertação de mestrado Corpos e Faces por Todas as Partes: um estudo dos artefatos antropomórficos no design contemporâneo brasileiro, desenvolvida no Programa de Pós-Graduação em Design da UFPE; que teve como objetivo geral analisar e categorizar os artefatos do design contemporâneo desenvolvidos e publicados no Brasil entre os anos de 2000 e 2014 e que utilizam o antropomorfismo como elemento de configuração.

Essa delimitação espaço-temporal se deu a partir da observação da recorrência desses artefatos nas principais instâncias de legitimação do campo do design, tais como publicações, concursos e premiações no Brasil nos últimos anos.

\section{DESENVOLVIMENTO}

\subsection{Antropomorfismo e Design}

O primeiro desafio da pesquisa foi tentar compreender o conceito de antropomorfismo e sua relação com o campo do Design, a fim de delimitar o escopo teórico sobre os artefatos antropomórficos. Grande parte dos estudos que tratam da teoria do antropomorfismo estão circunscritos em outras áreas de conhecimento, e se concentram, em sua maioria, em tentar desvendar como e por que as pessoas antropomorfizam, elaborando teorias específicas nesse sentido.

No contexto do Design, as pesquisas que tratam do antropomorfismo ainda são incapazes de revelar claramente os limites da abordagem. Sendo assim, foi necessária uma reflexão sobre as principais conceituações do antropomorfismo no sentido de compreender suas dimensões e, a partir de então, conduzir as discussões sobre sua aproximação com o Design.

Stewart Guthrie explica o antropomorfismo como sendo "a atribuição de características humanas a objetos e eventos não humanos." (1993, p. 3). Segundo o autor, essas características compreendem a "forma física, crenças, sentimentos e emoções". Já os pesquisadores Carl Di Salvo e Francine Gemperle utilizam o termo "formas antropomórficas" para designar os artefatos projetados para refletir atributos humanos. Nesse contexto, o termo "forma" está relacionado à "expressão do produto", o que inclui a sua "aparência física", suas "qualidades comportamentais" e as "interações" promovidas por ele, Como explicam Di Salvo; Gemperle (2003, p.67).

Esses conceitos apontam para as duas principais aborgadens de conceituação da forma antropomórfica do Design. Uma delas diz respeito à questões tangíveis da forma, ou seja, fala das representações da aparência física propriamente, enquanto a outra refere-se a aspectos subjetivos da figura humana, quando são representados ou extraídos dos artefatos, características como sentimentos, emoções, crenças e comportamentos, propriamente humanos.

Quem discute brevemente essa dimensão subjetiva das formas antropomórficas é Donald A. Norman no livro Design Emocional. Norman (1998, p. 162), conceitua antropomorfismo como sendo a "atribuição de motivações, crenças e sentimentos humanos a animais e a objetos inanimados". 
No texto, o autor trata da temática a partir da interação afetiva entre os artefatos e indivíduos. Norman (1998, p. 162) diz que "tratamos raquetes de tênis, bolas e ferramentas de mão como seres animados, elogiando-as verbalmente quando fazem um bom trabalho para nós, ou culpando-as quando se recusam a funcionar como havíamos desejado". Esse ato de inferir personalidade, humor, sentimentos, empatia e emoções aos artefatos fazem referência às representações subjetivas da forma humana. O antropomorfismo, nesse caso, só pode ser identificado quando se observa a resposta ou reação de um indivíduo ao interagir com um artefato antropomórfico.

Em relação às representações tangíveis da figura humana, o exemplo vem de Lidwell, Holden e Buttler (2010). No livro Universal Principles of Design, os autores tratam das formas antropomórficas em relação ao estímulo perceptivo que é criado a partir da aparência física humana. A mamadeira Adiri (Figura 4), por exemplo, imita o formato e textura de uma mama feminina como forma de criar uma aproximação com a realidade através do estímulo tátil e visual. Esse exemplo mostra que uma das possibilidades da forma antropomórfica é a mimese de partes do corpo humano.

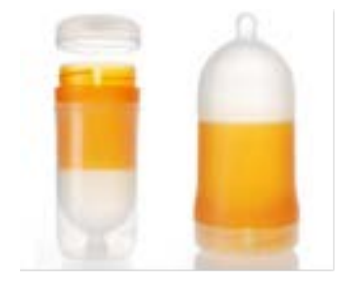

Figura 4 - Mamadeira Adiri.

Fonte: www.laifi.com

Outro exemplo citado pelos autores fala da representação de proporções do corpo humano. Segundo Lidwell, Holden e Buttler (2010), a garrafa da Coca-Cola sofreu mudanças em sua forma (Figura 5), passando a apresentar um formato mais curvilíneo e sinuoso, ao invés das formas duras e geométricas que costumava ter. A transformação ocorreu, segundo os autores, por motivos mercadológicos, visto que a maioria dos compradores na época eram mulheres. Essa nova conformação também traz projeções semânticas como sensualidade, feminilidade e vitalidade.

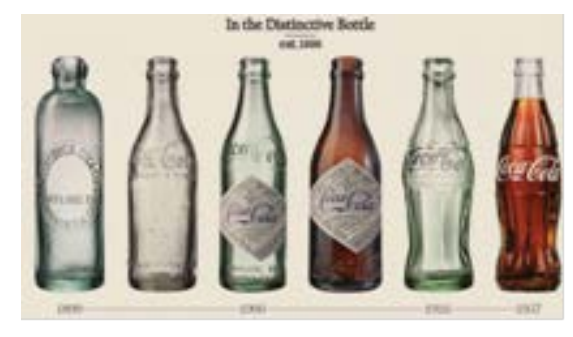

Figura 5 - Evolução das garrafas de Coca-cola.

Fonte: vos.lavoz.com.ar

Além dessas, outras representações se apresentam, como a imitação das formas de um rosto. Esse tipo de assciação é muito comum no design de automóveis, através do conjunto formado pelos faróis, capô e radiador dos veículos, em que se percebe instantaneamente uma face. A respeito disso, Sudjic, comenta que: 
As coisas passaram a ser mais estudadas e intencionais desde os primórdios aparentemente inocentes do design de carros. Patrick LeQuement, que trabalhava para a Renault nos anos 1980 com instruções para fazer um carro que fosse tão engraçadinho quanto o mascote da família, produziu o Twingo (Figura 6). Ele enfrentou a tarefa introduzindo as características antropomórficas mais óbvias: faróis que pareciam olhos e um sorriso de vencedor para a grade de radiador (SUDJIC, 2010, p. 42).

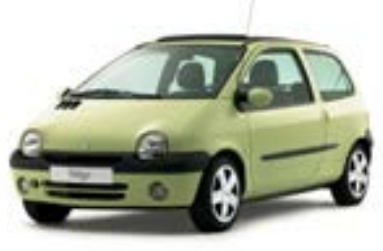

Figura 6 - Renault Twingo

Fonte: vos.lavoz.com.ar

Ainda dentro dessa abordagem que compreende a representação de características humanas tangíveis, é possível incluir formas antropomórficas que mimetizam a estrutura, movimentos e posições do corpo humano, como o dobrar das articulações, o sentar, o ficar de pé, etc. Neste sentido, Di Salvo e Gemperle (2003) apresentam a escova de louças da empresa alemã Koziol (Figura 7). O produto é constituído na forma de um corpo humano, sustentado por uma base em forma de pé, que serve para mostrar o modo de repouso do produto, "de pé". Outro exemplo citado pelos autores é o keneeling bus. O ônibus possui um mecanismo hidráulico que faz com que ele "ajoelhe" para que seus usuários, aproximando-se do meio fio de modo que as pessoas possam entrar com maior facilidade.

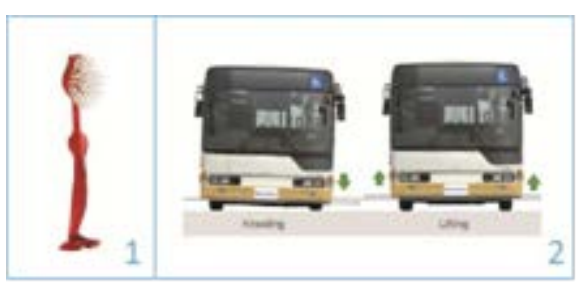

Figura 7 - Escova de louças, da Koziol e Kneeling bus, da Mitsubishi.

Fonte: Elaborado pelo autor, com base na pesquisa realizada.

\subsection{Metodologia}

A pesquisa tem caráter metodológico qualitativo e um alcance exploratóriodescritivo, que permite inicialmente uma maior aproximação com a questão do antropomorfismo e a partir disso, o estabelecimento e comprensão dos diversos ângulos e dimensões de sua relação com o Design.

Nesse contexto, o estudo se desenvolve em quatro etapas principais, que constituem: levantamento, análise, categorização e resultados, regidas por métodos e ferramentas específicas. Este artigo, no entanto, concentra-se apenas nessas duas últimas fases do processo metodológico.

A fase de levantamento é composta de uma revisão bibliográfica, que aborda questões que envolvem a tríade design-antropomorfismo-estética, além de um estudo exploratório em livros e revistas especializados, concursos, prêmios e exposições de 
Design, com a finalidade de mapear os artefatos com características antropomórficas no contexto do design brasileiro.

Para esta primeira parte, o Método de Procedimento Histórico ofereceu suporte, possibilitando uma investigação retrospectiva do fenômeno. De acordo com Lakatos (2009, p. 88-89), "partindo do princípio que as atuais formas de vida social, as instituições e os costumes têm origem no passado, é importante pesquisar suas raízes, para compreender sua natureza e função". Essa abordagem permitiu uma observação panorâmica do uso do antropomorfismo no âmbito do design brasileiro, apontando o período e o contexto de maior incidência dessas formas.

Essa primeira parte resultou na construção das bases teóricas da pesquisa, importantes para a realização dos procedimentos e etapas seguintes, e na composição da primeira amostragem de artefatos.

Como resultado do mapeamento, obteve-se a primeira amostragem, composta por uma série de 45 produtos, distribuídos entre mobiliário, utilidades domésticas, utensílios de cozinha, embalagens e produtos de escritório. Esses artefatos foram observados, sendo posteriormente reduzidos a um conjunto de 32 artefatos. 0 critério utilizado para a redução da amostra foi a variedade de soluções projetuais dentro de cada tipologia de produto. As tipologias: embalagem e produtos de escritório foram excluídas do corpus de análise por conter produtos com representações antropomórficas muito semelhantes entre si, ocasionando uma redundância no resultado da análise.

Definido o corpus da pesquisa, o artefatos foram submetidos à etapa de análise, que permitiu a leitura e decodificação dessas formas. Os critérios dessa análise foram definidos com base no referencial teórico da pesquisa e utiliza principalmente elementos da semiótica, organizados na forma de uma ficha de análise.

A etapa seguinte trata da classificação desses produtos. Uma vez analisados, os dados obtidos dessa "leitura" foram cruzados, identificando-se analogias e diferenças que permitiram o agrupamento desses artefatos em categorias.

Para execução dessas últimas etapas, foi utilizado o Método de Procedimento Comparativo, que permitiu o confronto dos objetos e dos dados da análise, fornecendo elementos para a categorização.

A última etapa consistiu na interpretação dos dados, conclusão e desdobramentos da pesquisa. Nesta fase, foi feita uma leitura crítica das análises e da categorização, elencando-se as principais conclusões do estudo e apresentando possíveis desdobramentos para a pesquisa.

\subsection{Análise}

O procedimento de análise dos artefatos tem como principal fundamento os princípios da semiótica. Segundo Niemeyer (2003, p. 19), a principal utilidade deste campo de estudo seria justamente "possibilitar a descrição e a análise da dimensão representativa (estruturação sígnica de Objetos, processos e fenômenos em várias áreas do conhecimento humano)".

Como visto, os artefatos antropomórficos se valem de elementos estéticos que assemelham-se às características humanas no sentido criar um estímulo perceptivo para o observador. Trazendo para o contexto da Semiótica, podemos dizer que esses elementos funcionam como signos da "forma" humana que têm por objetivo produzir significados e atitudes interpretativas na mente de quem percebe. 
De acordo com Santaella (2005, p. 59), "a semiótica nos habilita a compreender o potencial comunicativo de todos os tipos de mensagens, nos variados efeitos que estão aptas a produzir no receptor. Esses efeitos vão desde o nível puramente emocional, sensório, até os níveis metafóricos e simbólicos".

Cada um desses artefatos, no entanto, possui uma configuração (formatação) única e a mensagem transmitida vai depender da disposição e da combinação de seus elementos constitutivos. O intuito principal dessa Análise, portanto, é identificar esses signos que se referem à forma humana (signos antropomórficos) e decifrar suas significações, ou seja, as mensagens visuais transmitidas pela forma desses artefatos.

Nos sentido de decodificar as formas antropomórficas, foi proposta uma ficha de análise, estruturada em três partes: a primeira parte é essencialmente descritiva e traz informações técnicas do produto; a segunda parte tem caráter analítico e interpretativo e propõe identificar os elementos antropomórficos desses artefatos e decodificar as mensagens visuais manifestas; por fim, a última parte apresenta uma síntese interpretativa dos resultados da análise.

Para uma leitura sistemática desses artefatos, foi utilizado como referência a conhecida "tricotomia dos diferentes níveis de abordagem" do signo, a saber: "O Nível sintático ou Sintaxe (primeiridade)", o "Nível semântico ou Semântica (secundidade)", e o "Nível pragmático ou Pragmática (terceiridade)". (PIGNATARI, 2004, p.139)

No sentido de uma aproximação entre Semiótica e o Design, Braida e Nojima (2014) propõe uma correlação entre essas categorias universais da concepção triádica do signo e os elementos essenciais do design: forma, função e significado. Nesta perspectiva "A forma está sob o domínio da Primeiridade, o significado, sob domínio da Secundidade e a função sob domínio da Terceiridade". (BRAIDA; NOJIMA, 2014, p.24, grifos do autor). É a partir dessa concepção que se desenvolve o procedimento de análise.

Como recurso para analisar as "dimensões semióticas do design" (BRAIDA; NOJIMA, 2014) foram utilizados como referência os principais manuais que tratam de linguagem visual, como Sintaxe da Linguagem Visual, de Donis A. Dondis, e Princípios de Forma e Desenho, do autor Wucius Wong. Além dessas, referências que abordam as funções dos produtos, como Desenho Industrial, de Bernd Löbach, e os principais textos sobre estética de Gustavo Amarante Bomfim.

Os artefatos foram analisados individualmente a partir dessa sequência de tópicos propostos na ficha de análise, e como base nos resultados da síntese interpretativa foram submetidos à Categorização.

\subsection{Categorização}

A técnica de categorização, segundo Bardin (2011):

consiste em classificar os diferentes elementos nas diversas gavetas
segundo critérios susceptíveis de fazer surgir um sentido capaz de introduzir
uma certa ordem na confusão inicial. É evidente que tudo depende, no
momento da escolha, dos critérios de classificação, daquilo que se procura
ou que se espera encontrar (BARDIN, 2011, p. 43).

Desse modo, foram identificadas unidades de semelhança entre os artefatos, que permitiram a sua classificação em três categorias gerais e, dentro dessas, mais seis subcategorias. O critério de classificação foi determinado, principalmente, pelo nível e 
pelo tipo de interação que essas formas antropomórficas proporcionam a seus usuários.

É preciso ressaltar, no entanto, que essas categorias são intercambiáveis. Isto significa que um mesmo artefato pode apresentar mais de uma categoria por vez, ou mesmo, mudar de categoria se analisado a partir de um outro contexto. Existe, portanto, uma possibilidade de trânsito e coexistência entre as categorias.

\subsubsection{Categoria 1: Artefatos antropomórficos sedutores}

Formas antropomórficas que estabelecem relações exclusivamente situadas no nível psicológico de uso, promovendo interações emocionais, no sentido de despertar prazer e bem-estar, estabelecendo um diálogo lúdico, ou ainda como forma de desencadear a sensação de estranhamento. Suprem, portanto, necessidades subjetivas vinculadas aos aspectos psicológicos da percepção sensorial dos indivíduos.

Dentro dessa categoria descam-se duas subcategorias, os artefatos antropomórficos sedutores subliminares (Figura 8) e os artefatos antropomórficos objetivos (Figura 9). O primeiro grupo com artefatos que se caracterizam por representarem a forma humana de maneira mais sútil, com elementos que muitas vezes são quase que imperceptíveis à primeira vista. São classificados nesse grupo os artefatos abaixo listados: (1) chaise Longue Lili, do designer Ado Azevedo, a (2) poltrona costa, da Furf Design, e a (3) Smile Chair, da Doimo Brasil.

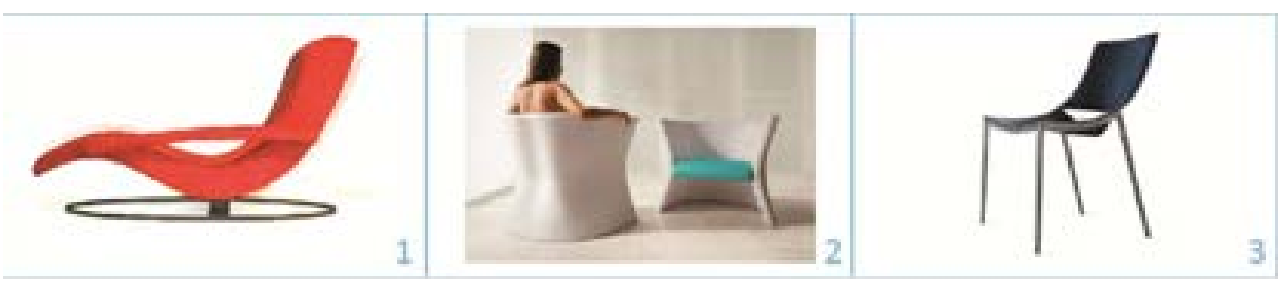

Figura 8 - Artefatos antropomórficos sedutores subliminares.

Fonte: Elaborado pelo autor, com base na pesquisa realizada.

Ao contrário do primeiro, o segundo grupo trata dos artefatos em que a forma humana é representada de maneira mais literal e, portanto, geralmente seguida de um aspecto lúdico muito forte. Essa subcategoria é composta pelos seguintes artefatos: (1) estante niño e niña, do arquiteto Henrique Steyer; (2) cadeira pictograma, da Quadrante Design; (3) conjunto de plaina e garfo para queijos, da Hércules; e o (4) feliz armário, da TokStok.

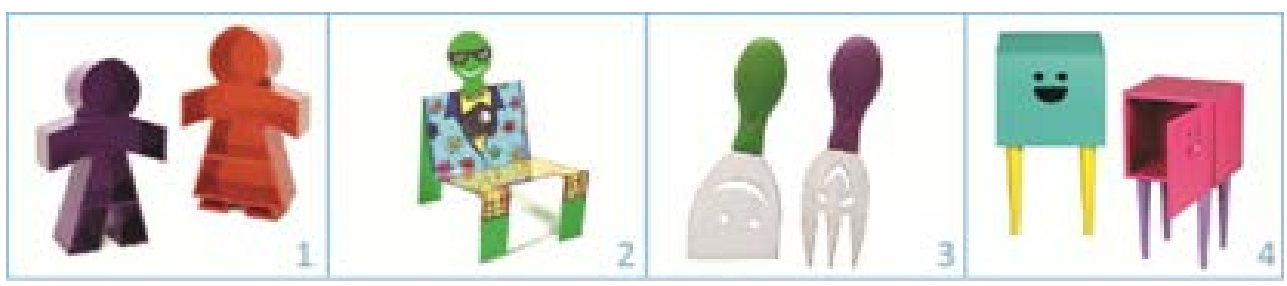

Figura 9 - Artefatos antropomórficos sedutores objetivos.

Fonte: Elaborado pelo autor, com base na pesquisa realizada. 


\subsubsection{Categoria 2: Artefatos antropomórficos contextuais}

Formas antropomórficas que estão relacionadas à memória de valores sociais e culturais dos usuários e grupos sociais. A configuração desses artefatos toma como base elementos singulares e específicos que fazem parte do imaginário coletivo de um determinado grupo social, no sentido de criar relações cuja motivação é primeiramente emocional.

É possível dizer que essa classe de artefatos carrega, em sua materialidade, elementos representativos de contextos sociais e culturais, tanto que é necessário compartilhar do mesmo repertório simbólico e imagético para que se possa decodificálos. A leitura seguramente não será a mesma para um indivíduo que não reconheça ou esteja envolvido naquele contexto específico. Essa categoria é composta por duas subcategorias.

A subcategoria de artefatos antropomórficos contextuais culturais (Figura 10) trata dos ícones e elementos da cultura brasileira, que, em tese, fazem parte do imaginário coletivo da população local. São classificados nesse grupo: o (1) banco pererê e o (2) banco zé, ambos do designer Ademário Santos; o (3) porta esponça de aço virgulino; a (4) escova para louças Sting e a (5) colher para sorvete tanga, produtos da Ikko Design; e o (6) cabideiro totem tribal, da Quadrante Design.

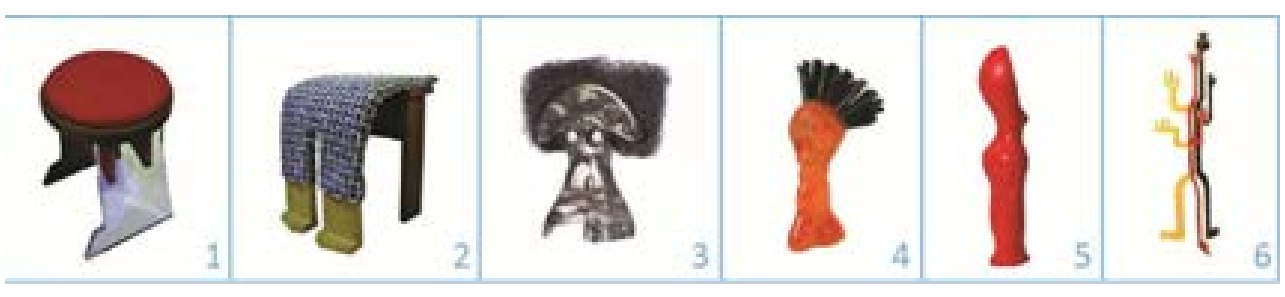

Figura 10 - Artefatos antropomórficos contextuais culturais. Fonte: Elaborado pelo autor, com base na pesquisa realizada

O segundo grupo constitui os artefatos antropomórficos contextuais de gênero (Figura 11). Representa essa subcategoria, o (1) conjunto de utensílios de silicone, da Hércules, cujas formas ressaltam a figura feminina. A forma, neste caso, faz uma referência à associação convencionada pela sociedade que vincula a imagem da mulher com o trabalho doméstico.

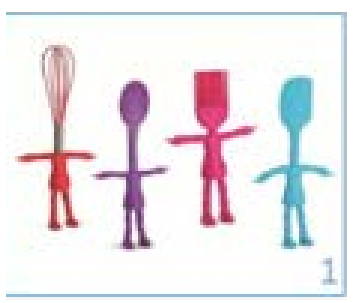

Figura 11 - Artefatos antropomórficos contextuais de gênero.

Fonte: Elaborado pelo autor, com base na pesquisa realizada.

\subsubsection{Categoria 3: Artefatos antropomórficos informacionais}

Nesta categoria, os artefatos se valem da função estética para explicar aspectos do uso ou funcionamento do produto. As metáforas criadas, representando formas, 
movimentos, posições e posturas, funcionam como uma maneira de ajudar o usuário a intuir, através da percepção, maneiras de interagir objetivamente com esses produtos.

Essa categoria divide-se em duas subcategorias. Na primeira, os artefatos antropomórficos informacionais de uso direto (Figura 12), refere-se aos artefatos cujas formas antropomórficas estabelecem uma relação direta com uso do produto. Os "braços" servem para sustentar, as "mãos" para segurar, as "bocas" para abocanhar, os "ombros" para apoiar, e assim sucessivamente. São classificados nessa subcategoria: o (1) aparador mordomo e o (2) bricolagem, da Quadrante Design; os (3) abridores de garrafa, da Hércules; (4) O difusor Deva Sun, de Sidnei Rufca; o (5) Pazzo dosador de espaguete, de Pedro Braga e Marcelo Lobo; o (6) pegador de gelo, da Hércules; o (7) cabide croqui, de Ronaldo Fraga; a (8) estante seguraí, da Quadrante Design; e o (9) cabideiro rapel, de Felipe Sarmento.

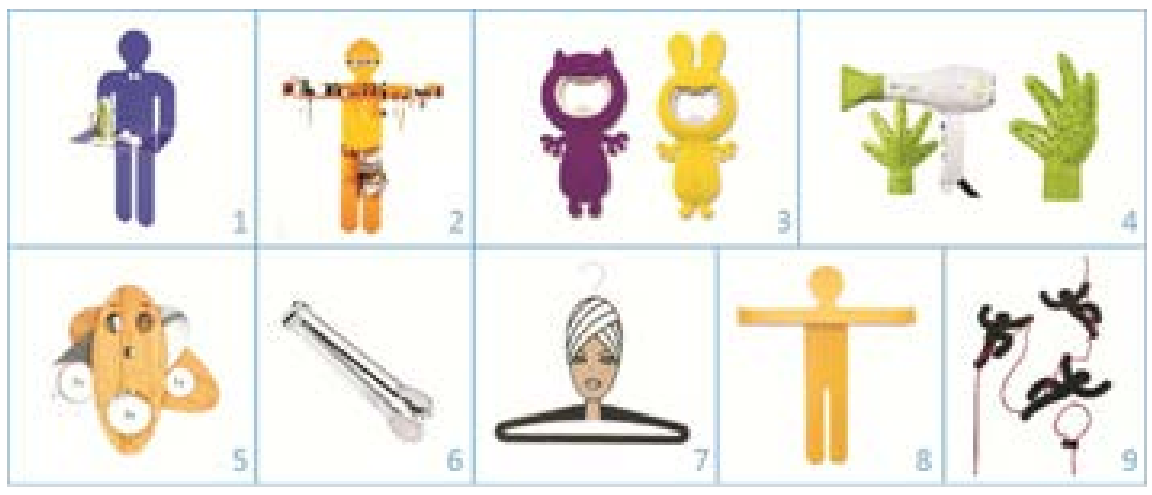

Figura 12 - Artefatos antropomórficos informacionais de uso direto.

Fonte: Elaborado pelo autor, com base na pesquisa realizada

Na segunda subcategoria estão os artefatos antropomórficos informacionais de uso sugerido (Figura 13), e refere-se ao conjunto de artefatos cuja forma sugere o uso do produto de maneira indireta, indicando um movimento, uma ação ou um posicionamento em relação ao objeto. Pertencem a esta subcategoria: o (1) banco people, da Quadrante Design; a (2) tomtom, da Furf; o (3) açucareiro Salvatore, da Ikko Design; o (4) conjunto de Hashi, da Hércules; o (5) conjunto de talheres infantis, da Hércules; o (6) conjunto de talheres da Brinox; a (7) luminária \#prontofalei, da QuesttoNó, o (8) cofre vingança do porquinho; e a (9) luminária saudade, ambos da Furf Design.

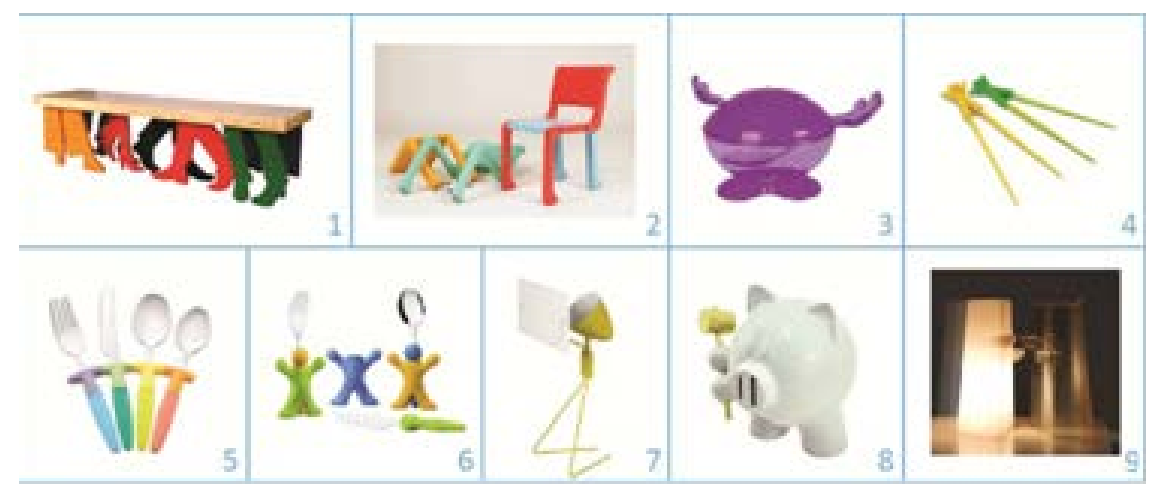

Figura 13 - Artefatos antropomórficos informacionais de uso sugerido. Fonte: Elaborado pelo autor, com base na pesquisa realizada 


\section{CONCLUSÃO}

Ao analisar a estética desses artefatos foi possível constatar o potencial comunicativo das formas antropomórficas que, ao contrário do que se mostram à primeira vista, não se limitam a desencadear apenas prazer contemplativo por intermédio da forma, mas, muito além disso, são capazes de interagir com seus espectadores em níveis mais profundos, sugerindo atitudes e motivando comportamentos.

Esses artefatos de fato priorizam a forma visual. O principal o objetivo dos designers ao configurar produtos com características antropomórficas é o de estimular a percepção dos usuários por meio da visualidade, desencadeando inicialmente relações cognitivas e emocionais e, a partir disso, proporcionar outras possibilidades de interação. É baseado nesse primeiro contato entre o produto e o espectador que as outras funções surgem a ele entrelaçadas, desencadeando novos sentidos e significados.

Ao analisar esses artefatos, foi possível identificar os principais significados e dimensões do antropomorfismo no design, apresentados sob a forma de categorias e subcategorias, as quais representam os propósitos principais a partir dos quais as características antropomórficas são utilizadas na configuração dos artefatos.

Cada uma dessas categorias identificadas, possibilita uma série de novos caminhos para se aprofundar os estudos das formas antropomórficas no âmbito do Design. A categoria que se refere aos artefatos antropomórficos sedutores sugere caminhos para o estudo dos objetos sobre o viés da psicologia cognitiva, do design emocional e do design experencial. A categoria que fala dos artefatos antropomórficos contextuais indica aproximações em relação ao estudo de formas culturalmente apropriadas. Sobre isso, Di Salvo e Gemperle (2005) explicam que cada cultura tem uma forma de antropomorfizar, possuem também diferentes representações do corpo humano, ideias e crenças sobre as formas antropomórficas. Compreender essas especificidades permite ao designer empregar de forma consciente formas antropomórficas correspondentes a contextos culturais específicos, respeitando as diferenças culturais. No sentido contrário, permite também compreender particularidades de determinados grupos sociais a partir da análise de suas representações antropomórficas (de sua cultura material).

Por fim, a categoria que trata dos artefatos antropomórficos informacionais, permite o encontro do antropomorfismo com áreas como a ergonomia, com o conceito de affordances ${ }^{2}$, ou com estudos sobre usabilidade: avaliando a experiência com o produto a partir do seu uso intuitivo.

Nesse contexto, ressaltamos a versatilidade com que as atuam as formas antropomórficas nos projetos de design, podendo ser empregadas em diversos

\footnotetext{
2 "O termo affordance refere-se à percepção e às propriedades reais da coisa, primordialmente àquelas propriedades fundamentais que determinam como ela poderia ser usada [...] Tais reconhecimentos fornecem fortes indícios que se saiba como as coisas operam. Puxadores de portas são feitos para serem empurrados. Maçanetas são feitas para girar. Encaixes são feitos para coisas serem colocadas dentro deles. Bolas são feitas para serem jogadas e quicarem. Quando esses reconhecimentos são tomados como vantagens, o usuário sabe o que fazer apenas olhado-as: não é necessário desenho, marca ou instrução (NORMAN, 1988, p. 9, tradução livre)". O termo inglês affordance, deriva do verbo inglês "to afford", que significa "prover, conceder", etc., e que, nesse sentido, relaciona-se à capacidade dos objetos de "intuírem" sua função, isto é, de terem em seu aspecto formal uma autoexplicação para sua função.
} 
contextos e com diferentes finalidades. Apesar de análise ter sido realizada no âmbito do design brasileiro, o modelo de análise e a categorização pode ser replicado à formas antropomórficas provenientes de outros contextos.

\section{REFERÊNCIAS}

BARDIN, Laurence. Análise de Conteúdo. São Paulo: Edições 70, 2011.

BRAIDA, Frederico; NOJIMA, Vera Lúcia. Tríades do Design: Um olhar semiótico sobre a forma, o significado e a função. Rio de Janeiro: Rio Book's, 2014.

DE BOTTON, Alain. A arquitetura da felicidade. Rio de Janeiro: Rocco, 2007.

DI SALVO, Carl; GEMPERLE, Francine. From seduction to fulfillment: The Use of Anthropomorphic Form in Design. In: DDPI'03 Conference of Designing Pleasurable Products and Interfaces 2003, 1., 2003, Pittsburg. Proceedings of the 2003 International Conference of Designing Pleasurable Products and Interfaces. Pittsburg: ACM Press, 2003. P. 67-72.

GUTHRIE, Stewart. Faces in the Clouds: A New Theory of Religion. New York: Oxford University Press, 1993.

LAKATOS, Eva Maria; MARCONI, Maria de Andrade. Metodologia do Trabalho Científico. 7.ed. São Paulo: Atlas, 2013.

NIEMEYER, Lucy. Elementos da Semiótica Aplicados ao Design. Rio de Janeiro: 2AB, 2003.

NORMAN, Donald A. Design emocional.São Paulo: Rocco, 2008.

PIGNATARI, Décio. Semiótica da arte e da arquitetura. 4.ed. São Paulo: Ateliê Editorial, 2004.

SANTAELLA, Lúcia. Semiótica Aplicada. São Paulo: Pioneira Thomson Learning, 2005.

SUDJIC, Deyan. A Linguagem das Coisas. Rio de Janeiro: Intrínseca, 2010. 